\title{
DIFERENÇAS DO PROCESSO DECISÓRIO DO JUDICIÁRIO E DOS PODERES POLÍTICOS
}

Carlo José Napolitano ${ }^{1}$

NAPOLITANO, C. J. Diferenças do processo decisório do judiciário e dos poderes políticos. Rev. Ciênc. Juríd. Soc. UNIPAR. Umuarama. v. 18, n. 1, p. 87-104, jan./jun. 2015.

RESUMO: O presente estudo é parte integrante do trabalho de doutoramento em que se investigou a hipótese de judicialização da política no Supremo Tribunal Federal. O estudo que se apresenta subsidiou o trabalho de doutoramento no sentido de apontar algumas diferenças existentes nos processos decisórios judiciários e nos políticos e definir se a hipótese de judicialização se confirmava. O presente trabalho visa a exercitar o apontamento dessas diferenças, tendo em vista a escassez de bibliografia específica sobre o tema e a imprecisão teórica na interpretação dessas diferenças.

PALAVRAS-CHAVE: Processo decisório; Política; Direito; Judiciário.

\section{INTRODUÇÃO}

O presente estudo parte do pressuposto que os processos decisórios no judiciário diferem dos processos decisórios no âmbito do legislativo e do executivo, muito embora alguns autores indiquem que a interpretação dessas diferenças são imprecisas.

No entanto, tem-se aqui a premissa de que há no poder judiciário um modo peculiar para a tomada de decisões, sendo essas regras pré-estabelecidas pelas leis processuais.

O trabalho que segue tem cunho eminentemente bibliográfico, tendo a preocupação de analisar a teoria jurídica e política, nacional e estrangeira, relativa ao tema proposto.

Importante relembrar que o presente trabalho é um exercício de interpretação e reflexão sobre essas diferenças, como será visto.

DOI: https://doi.org/10.25110/rcjs.v18i1.2015.5413

${ }^{1}$ Professor do Departamento de Ciências Humanas e do Programa de Pós-Graduação em Comunicação, da Faculdade de Arquitetura, Artes e Comunicação, UNESP/Bauru/SP, e-mail: carlonapolitano@faac.unesp.br. 


\section{APONTAMENTOS DAS DIFERENÇAS DOS PROCESSOS DECISÓ- RIOS}

A grande diferença encontrada entre o processo decisório judicial e os processos decisórios políticos reside no fato de o judiciário estar, pela legislação processual, obrigado a decidir, é um poder da república constrangido a tomar decisões.

É bom observar também, com Oliveira (2006, p. 18), que "o processo de decisão judicial é cercado por segredo e mistério [...]. Os procedimentos são ritualizados, acompanhados de pompa e cerimônia, e são conduzidos numa linguagem largamente ininteligível para os leigos.”.

Além disso, o poder judiciário somente toma decisões dentro de um processo judicial, entendido como relação jurídica que envolve o autor-réu-juiz, sendo utilizado pelo Estado para o exercício de sua função jurisdicional, a aplicação e a interpretação do direito. Por ser uma relação jurídica, impõem-se aos seus atores, autor-réu-juiz, direitos e deveres que necessariamente devem ser respeitados (MARCATO, 1994).

Esses direitos e deveres estão previstos na Constituição Federal e nos códigos de processo e dizem respeito a algumas regras que devem ser respeitadas pelas pessoas envolvidas na relação jurídico processual. São normas "que propiciam às partes a plena defesa de seus interesses e ao juiz os instrumentos necessários" (THEODORO JUNIOR, 1998, v. 1, p. 42) para a tomada de decisões.

Essa gama de direitos e deveres é denominada de princípio do devido processo legal, que permite "um procedimento justo, fair, onde as partes possam, com igual peso e espaço, apresentar seus argumentos" (VIEIRA, 2002, p. 229). Do princípio do processo legal decorrem os princípios da imparcialidade do juiz, da igualdade das partes, da ação ou da inércia, do contraditório, da lealdade processual, da ampla defesa, do impulso oficial e da inafastabilidade da jurisdição.

Esses princípios estão relacionados aos aspectos formais do processo, sem que haja indagações ou formulações de princípios atinentes aos aspectos substantivos. Segundo Souza (2005, p. 72-73), nos procedimentos judiciais prevalecem os seus aspectos formais, com uma "predominância da processualística e dos meandros técnicos em detrimento das questões substantivas.".

Pelo princípio da igualdade entende-se que autor e réu devem ser considerados e tratados pelo juiz ou tribunal de forma igual dentro da relação processual, decorrendo dessa característica o princípio do contraditório, que significa que sempre quando houver manifestação de uma das partes no processo, necessária se torna a oitiva da outra parte, sob pena de cerceamento do direito de defesa.

A lealdade processual pressupõe que autor e réu dentro do processo 
devem seguir o enunciado da lei, não se permitindo, por exemplo, a utilização de provas obtidas por meios ilegais ou de expedientes não previstos na legislação processual.

O princípio da ampla defesa garante aos participantes do processo a utilização de todos os meios e condições, desde que legais, para defender seus interesses que estão em jogo.

A lei também prevê o princípio da inércia do judiciário, que significa que qualquer juiz ou tribunal somente poderá agir a partir do momento que for acionado por um interessado, conforme dispõe o artigo $2^{\circ}$ do código de processo civil $^{2}$. A jurisdição é inerte, e somente pode ser exercitada a partir do momento em que for acionada, não podendo haver início e consequentemente decisão de processos de ofício. O judiciário é, portanto, um poder "inerentemente passivo e precisa ser acionado por atores externos para que tenha qualquer efeito." (TAYLOR, 2007, p. 231).

Para Carvalho (2005), essa diferença quanto à iniciativa deve ser levada em consideração, pois enquanto os poderes políticos são livres para propor uma lei, e são capazes de decidir quando e como uma nova lei será elaborada e aprovada, o judiciário está totalmente dependente de uma iniciativa externa.

Trata-se, no direito brasileiro, do chamado princípio da ação. Segundo esse princípio, o titular de um direito tem a prerrogativa de ingressar em juízo exigindo uma manifestação jurisdicional para o seu caso específico. $\mathrm{O}$ autor da ação é quem decide se inicia ou não o processo, sendo que este será analisado e julgado por um juiz que necessariamente não deve ter interesse e nem relação com o caso que irá decidir. Fala-se, portanto, do princípio da imparcialidade do juiz que pressupõe que nenhum juiz ou tribunal deve decidir um caso por interesse pessoal, devendo decidir a questão da maneira como ela lhe foi apresentada, não sendo permitido, em regra, ao juiz buscar outras fontes de informação a não ser aquelas apresentadas pelas partes.

O princípio da ação tem por finalidade inibir que o juiz que inaugura o processo acabe psicologicamente ligado a ele o que possibilitaria um julgamento favorável, ocasionando certamente ausência de imparcialidade do magistrado. Essa técnica processual difere do chamado processo inquisitivo, no qual, todas as funções dentro do processo ficam a cargo de um único órgão, ou seja, o juiz que inicia o processo produz as provas e julga (CINTRA; GRINOVER; DINAMARCO, 1979) 3

${ }^{2} \mathrm{O}$ artigo $2^{\circ}$ da lei 5.869, de 11 de janeiro de 1973, Código de Processo Civil, dispõe que "nenhum juiz prestará a tutela jurisdicional senão quando a parte ou o interessado a requerer, nos casos e formas legais." (BRASIL, 1973)

${ }^{3} \mathrm{O}$ fato de o judiciário ser um órgão inerte e reativo remonta ao Estado de Direito, quando as funções do Estado foram dividas em três órgãos, antes reunidos nas mãos de um mesmo agente, na tentativa de atribuir-se certa racionalidade na aplicação da lei. Para Mangabeira Unger (1976) foi uma forma 
Para Cappelletti (1993) existem limites processuais e virtudes passivas que diferenciam profundamente os atos jurisdicionais dos de natureza política. Além disso, os atos políticos são parciais, ao passo que ao judiciário pressupõe-se a imparcialidade e a neutralidade nos julgamentos.

O juiz ou tribunal é obrigado a decidir e assim que for acionado deve conduzir o processo até o fim para solucionar a questão posta em juízo, tendo em vista o disposto no artigo 126 do código de processo civil. Trata-se do princípio da indeclinabilidade da prestação jurisdicional. Também o judiciário necessariamente deverá, nos seus juízos decisórios, pautar-se pela lei ${ }^{4}$, e somente poderá decidir a questão colocada em juízo nos limites em que foi proposta, não podendo apreciar questões não levantadas pelas partes ${ }^{5}$, à exceção do decisório no controle de constitucionalidade. Trata-se do princípio do impulso oficial, que significa que o juiz ou tribunal não pode exercer o juízo discricionário de não decidir; deverá necessariamente levar o processo até seu fim e proferir uma decisão dentro de um processo, seja concedendo o direito ou negando-lhe ${ }^{6}$. Não se desconsidera que a morosidade típica do judiciário brasileiro é uma forma de burlar essa regra processual.

Ainda, no processo decisório judicial, há a necessidade dos juízes e tribunais, ao proferirem suas decisões, exporem suas razões de decidir, ou nas palavras da constituição brasileira, o dever de fundamentar as decisões ${ }^{7}$. Para Cappelletti (1993, p. 98), essa técnica pode ser encarada como uma forma de convencimento do público da legitimidade das decisões proferidas pelo judiciário e de assegurar ao cidadão que as decisões jurídicas "não resultam de capricho ou idiossincrasias e predileções subjetivas dos juízes".

No mesmo sentido, Vieira (1999, p. 216) aponta que

o ponto crucial de controle desta atividade argumentativo-decisória é

encontrada pela aristocracia de controlar o acesso ao judiciário por parte da burguesia, órgão responsável, na separação de poderes, pela aplicação da lei. Para Bobbio, Matteucci e Pasquino (1991, p. 249) essa forma de divisão de poderes, conhecida como o ideal clássico do governo misto "é a mais antiga versão da divisão dos poderes, é a que teve maior sucesso na Europa, na primeira metade do século XIX, por garantir, em uma fase histórica de transformações políticas, a manutenção de um certo equilíbrio social entre as classes.”

${ }^{4}$ Artigo 126 do Código de Processo Civil: "O juiz não se exime de sentenciar ou despachar alegando lacuna ou obscuridade na lei. No julgamento da lide caber-lhe-á aplicar as normas legais; não as havendo recorra à analogia, aos costumes e aos princípios gerais de direito." (BRASIL, 1973)

${ }^{5}$ Artigo 128 do Código de Processo Civil: "O juiz decidirá a lide nos limites em que foi proposta, sendo-lhe defeso conhecer de questões, não suscitadas, a cujo respeito exige a iniciativa da parte." (BRASIL, 1973)

${ }^{6}$ Artigo 262 do Código de Processo Civil: "O processo civil começa por iniciativa da parte, mas se desenvolve por impulso oficial.” (BRASIL, 1973)

${ }^{7} \mathrm{O}$ artigo 93, inciso IX da Constituição Federal dispõe que "todos os julgamentos dos órgãos do Poder Judiciário serão públicos e fundamentadas todas as decisões, sob pena de nulidade”. (BRASIL, 1988)

Rev. Ciênc. Juríd. Soc. UNIPAR, v. 18, n. 1, p. 87-104, jan./jun. 2015 
a obrigação de o magistrado fundamentar e justificar as razões que o levaram a uma determinada decisão. É esse imperativo - inexistente na esfera do legislativo.

Nas palavras de Moro (2004), a fundamentação das decisões dá legitimidade a elas.

É uma regra de consistência que configura no dever de fundamentação substancial, que deve ser observado especialmente para declarar uma norma inconstitucional (HABERLE, 1997 e MORO, 2004). Os juízes, desse modo, devem justificar e fundamentar suas decisões em todas as fases do processo decisório judicial.

Resumindo, segundo Koerner (2005, p. 15),

as decisões judiciais são eventos que ocorrem no interior de um quadro organizacional, com uma determinada distribuição de papéis e recursos, que prevê a participação de agentes externos à organização e uma ordem formalizada de ações, cuja seqüência, atribuições e lances são previamente delimitados.

Diferentemente do sistema de justiça, o sistema político tem regras decisórias que lhe são próprias. Por exemplo, ao sistema político é possível adiar e protelar as suas decisões, na espera de melhor oportunidade para a tomada de decisão, o tempo é uma das variáveis da política. O judiciário, contudo, não pode esquivar-se da decisão, sendo certo que somente poderá tomar uma decisão quanto for acionado por um agente externo a sua estrutura, não podendo tomar decisões de ofício, muito embora Taylor (2007, p. 231) apregoe que, no interior de um processo judicial, o tempo pode ser manipulado de acordo com a vontade da corte.

Se a corte quiser dar uma resposta rápida ao assunto pode usar das liminares para isso, caso queira protelar a decisão pode ser usado o mecanismo de vista para postergar. Há, portanto, segundo Taylor

uma capacidade considerável dos ministros do STF de controlar o timing e as consequências de seu impacto, seja sustentando políticas públicas que apóiam ou atrasando a derrota daqueles que eles acreditam ser de constitucionalidade duvidosa, porém preferíveis.

$\mathrm{Na}$ arena política, por sua vez, podem ser tomadas decisões por critérios de conveniência e oportunidade, diferentemente do judiciário, que deve agir ou decidir de forma vinculada à lei, não podendo decidir por outros critérios que não o estritamente legal. A tomada de decisões no judiciário deve ter como base de- 
cisões anteriores pré-ordenadas e definidas pelos outros dois poderes. Não cabe, portanto, ao judiciário tomar decisões tendo por base critérios outros que não os critérios da normatividade pré-existentes e previamente determinadas pelos poderes representativos, pois o judiciário não teria legitimidade democrática para fazer este tipo de escolha, apoiado em critérios extraconstitucionais ou legais, como, por exemplo, a alegação de comoção popular ou de eficiência econômica (VIEIRA, 2002).

O processo decisório judicial, segundo Vieira (2002), pauta-se pela obediência ao devido processo legal, à necessidade de imparcialidade do julgador e à obrigatoriedade de fundamentação das decisões. Ao passo que o processo decisório político pauta-se: primeiro pela maior discricionariedade, sendo permitida, por exemplo, ao legislativo a possibilidade de mudar e alterar as regras do jogo, pois é esse poder quem as define; segundo, os poderes políticos devem respeitar a regra da maioria, o que possibilita o uso de barganhas e compromissos; a terceira diferença diz respeito à parcialidade dos poderes políticos, pois representam interesses e ideologias; a última seria a vinculação de toda a sociedade às decisões políticas, sendo regra no processo judicial a vinculação somente às partes envolvidas no processo.

Segundo Shapiro e Sweet (2002) essa última característica seria crucial na distinção entre os processos decisórios, pois a decisão política é geral e a judicial é individualizada, além de a primeira ser prospectiva e a segunda, retrospectiva.

Vallinder (1994) aponta que as decisões políticas nas democracias são tomadas por assembleias eleitas, baseadas no princípio da maioria e decorrem de um debate público, livre e entre iguais. As decisões da justiça caracterizam-se por provirem de um colegiado especial, normalmente com treinamento específico, sendo que, em regra, as soluções dos conflitos judiciais se dão entre duas partes, dentro de um caminho regular e autoritário, com regras pré-ordenadas, verificando os fatos do caso e pesando os argumentos das partes em conflito. Também menciona que as decisões políticas têm efeitos prospectivos, ao passo que a decisão judicial é retrospectiva. ${ }^{8}$ Para esse autor, o processo decisório judicial difere do político, tendo em vista a diferença de atores, do método, da regra de decisão, dos efeitos da decisão e de suas implicações. O judiciário, então, caracteriza-se por configurar uma decisão envolvendo duas partes e um terceiro participante, o juiz. Decisão essa que é tomada tendo por base a oitiva de argumentos feita de forma aberta e pública e decidida por um juiz imparcial, em um caso individual, baseado em fatos e regras, sendo a decisão única e correta. Ao

${ }^{8}$ Para Habermas (2003, v. 1, p. 305-6), historicamente, a justiça volta seus olhos para o passado, para o que já foi decidido no passado pelo parlamento, ao passo que o legislador é que visualiza o futuro e a administração controla o presente. 
passo que o processo decisório político, tendo em vista os mesmos elementos apontados, caracteriza-se por envolver várias partes, basear-se em trocas e barganhas, muitas vezes levadas a cabo de portas fechadas, amparado na regra da maioria, no intuito de definir regras gerais e valores ou soluções politicamente possíveis.

Para Oliveira (2006) uma das principais diferenças entre os processos decisórios remete para a presença de agentes profissionalizados no âmbito do judiciário, ao passo que na arena política não.

Muito embora, não possa ser desconsiderado que haja profissionalismo em determinadas dimensões técnicas da política, como também pode haver avaliações exclusivamente políticas nas decisões judiciais, em especial, em questões envolvendo as relações entre os poderes da república.

Campilongo (2002, p. 34) também faz um relato minucioso a respeito dessas diferenças. Parte do pressuposto de que a "decisão judicial é entendida como o exercício de subsunção do fato à norma", o juiz está vinculado exclusivamente à lei.

Não se desconsidera, contudo, que a lei e a linguagem jurídica não são expressões unívocas e que por isso demandam a interpretação, que muitas vezes pode se apresentar de maneira divergente.

O judiciário estaria obrigado a tomar decisões, não poderia protelar, portanto. Para Campilongo (2002, p. 92), esse poder é o único constrangido a decidir, mesmo que essa obrigatoriedade restrinja-se apenas ao aspecto formalístico da questão, não abrangendo uma decisão de mérito. O legislativo e o executivo podem ou não decidir, sendo que podem socorrer-se de "estratégias de adiamento ou delegação do poder decisório", ao passo que a decisão judicial é imposta pelo sistema jurídico, não há no judiciário a não decisão.

No mesmo sentido, Faria (2004, p. 110) observa que "o sistema político pode adiar suas decisões à espera de melhor oportunidade para agir", já os tribunais não "podem deixar de decidir quando acionados pela sociedade.".

Ainda segundo Campilongo (2002, p.163), a própria "teoria jurídica cria diversos instrumentos para a atuação prática do "non liquet", compreendida como sendo a impossibilidade de o juiz não julgar, ou o poder de o juiz não julgar, por não saber como julgar, esquivando-se de decidir o mérito através de escusas formais.

Prossegue o autor afirmando que

provavelmente, o expediente mais comum para justificar decisões obrigatórias mais difíceis são as desculpas formais. Nulidades processuais, prescrições, vícios formais e falta de regularidade formal costumam funcionar como alívio e auxílio à obrigação de decidir. Alívio, pois permite uma decisão com economia de argumentos e amparada 
na lei. Auxílio, porque atuam como saída operacional aos dilemas judiciais. Usa-se o direito como desculpa para não aplicar o direito.

O Supremo, segundo Koerner (2005, p. 7), ao controlar a constitucionalidade dos atos normativos utiliza-se, predominantemente, desses aspectos formais, deixando muitas vezes de analisar a materialidade desses atos e decidindo por meio dessas desculpas formais. Lançaria, portanto, mão do direito como desculpa para não aplicar o direito, o que implica, muitas vezes, no arquivamento das ações por motivos processuais, sem uma análise do mérito da questão. As decisões do STF, no controle de constitucionalidade, no período pós-constituinte, foram no sentido de aparelhar o próprio tribunal, no aspecto formalístico, ao invés de julgar a materialidade das ações. A própria edição da lei 9.868/99 que regulamentou o controle de constitucionalidade é reflexo claro desse aparelhamento, desta forma, "são os próprios Ministros que decidem sobre seu papel institucional.”.

É importante frisar que o projeto de lei que resultou na lei 9.868/99 foi apresentado pelo executivo, após a constituição de uma comissão de juristas para elaboração de um anteprojeto de lei, tendo sido esse redigido pelo jurista Gilmar Mendes, Ministro do Supremo Tribunal Federal, seguindo as orientações contidas no Regimento Interno do STF, bem como na própria jurisprudência desse tribunal.

Da mesma forma, Maus (2000), ao analisar a história do tribunal constitucional alemão, observa que a competência daquele tribunal deriva de suas próprias decisões pretéritas.

A teoria constitucional alemã, em especial, no diz respeito ao controle de constitucionalidade das leis, exerce forte influência junto ao Supremo Tribunal Federal.

A hipótese apresentada por Maus (2000) pode ser transportada para a realidade brasileira, pois é o próprio Supremo quem vem definindo as regras e pressupostos formais para o controle de constitucionalidade. O Tribunal muitas vezes criou e ainda cria obstáculos processuais para não julgar e não decidir o mérito das ações a ele apresentadas.

Convém salientar que a obrigatoriedade de decidir e os critérios para a decisão judicial são impostos pelo poder político que institui as "premissas decisórias" (CAMPILONGO, 2002, p. 95) para o sistema jurídico.

Ao poder judiciário é dada a função de dar um basta ao conflito jurídico, dar uma decisão única e correta. Essa função decorre da compreensão do sistema jurídico como sendo completo e fechado. Contudo, nos dias atuais, devido à hiperinflação legislativa, à complexidade do sistema jurídico, à abertura e indeterminação dos conceitos legais e ao gigantismo da constituição podem abrir 
espaço para decisões contra a lei, ou contra o ordenamento jurídico supostamente fechado e completo, o que pode levar ao arbítrio (CAMPILONGO, 2002).

Mesmo com todas essas características do direito atual, a legislação processual brasileira não faculta ao juiz decidir tendo outros parâmetros que não aqueles determinados pelo sistema legal; os juízes não estão autorizados a decidirem com base em orientação política, econômica ou religiosa (CAMPILONGO, 2002), sendo esses argumentos admitidos nas decisões políticas.

Campilongo (2002, p. 90), também, menciona que as decisões políticas vinculam coletivamente, sendo "instrumentos de agregação de consenso", imensuravelmente maiores do que as decisões judiciais. No processo eleitoral, por exemplo, as decisões são tomadas por milhares ou milhões de cidadãos. A decisão judicial é monocrática ou colegiada, envolvendo no máximo dezenas de juízes. As decisões políticas possuem amplitudes comunicativas e argumentativas infinitamente maiores do que a do judiciário que fica restrito apenas aos critérios legais formulados no interior do processo.

Ainda conforme Campilongo (2002, p. 72), outras diferenças podem ser apontadas. Enquanto na esfera política a decisão baseia-se no conceito de alternância de poder entre governo e oposição, nas garantias às minorias, na periodicidade do processo eleitoral e principalmente na reversibilidade das decisões, o que permite um "contínuo incremento das possibilidades de escolha". No sistema judicial as decisões, em regra, não são reversíveis, pois quando tomadas, têm a garantia constitucional da coisa julgada, tornando-se a decisão imutável, indiscutível. ${ }^{9}$ Além disso, a decisão judicial não é controlada por outra instância de poder, somente é controlada pelo próprio ordenamento jurídico.

No mesmo diapasão está Habermas (2003, v. 2, p. 183) para quem "a justiça só pode mobilizar as razões que lhe são dadas, segundo o direito e a lei, a fim de chegar a decisões coerentes num caso concreto". Desse modo, na estrutura de divisão de poderes, cabe ao judiciário, precipuamente, a aplicação da lei a um caso concreto, ao passo que as decisões dos demais poderes podem ser controladas por outras instâncias e, em especial e em tese, pela vontade popular.

Muito embora, Habermas (2003, v. 1, p. 182), ao analisar a relação interna entre o direito e a política, compreenda que na modernidade, o direito empresta um formato jurídico ao poder político e organiza o funcionamento do poder do Estado, o que reforça o papel das decisões judiciais. Nesse sentido, aos tribunais é dada a prerrogativa de decidirem o que é e o que não é direito, e o poder judiciário, nessa medida "serve para a institucionalização política do direito.".

O executivo, como exemplo, pode controlar uma decisão do legislati-

${ }^{9}$ Segundo o Código de Processo Civil, artigo 467: “denomina-se coisa julgada material a eficácia que torna imutável e indiscutível a sentença” (BRASIL, 1973) 
vo por meio do veto, ao passo que o legislativo pode controlar essa decisão do executivo através da derrubada do veto. Contudo, ninguém pode derrubar a coisa julgada, nem mesmo por alterações legislativas.

Contudo, adverte Campilongo (2002) que tanto a decisão judicial quanto a política têm na constituição a sua fonte normativa. Entretanto, reside aí outra diferença entre a política e a justiça. A decisão política é programante, ao passo que a decisão judicial é programada pela decisão política, uma é prospectiva, a outra, retrospectiva.

O processo decisório político também se caracteriza por controlar a sua agenda decisória, o legislador ou o executivo é quem têm a iniciativa na construção dessa agenda "e seleciona os temas sobre os quais deseja decidir" (CAMPILONGO, 2002, p. 104). Contudo, devido ao princípio da ação ou da inércia do judiciário, esse poder não dispõe, em regra, de nenhum controle sobre as causas que tem que decidir. A sua agenda é definida por agentes externos, pelo autor da ação. Obviamente que existem exceções a essa regra, pois existe a possibilidade, atribuída pela Emenda Constitucional n. 45, do STF, por exemplo, fazer um juízo discricionário no julgamento dos recursos extraordinários e decidir quais processos irá analisar. Contudo, isso não é a regra, pois não caberia ao judiciário exercer um controle sobre sua agenda decisória.

Campilongo (2002, p. 104) também aponta uma diferença na fundamentação das decisões judiciais em relação às decisões políticas. Para este autor "o legislador está submetido a critérios de justificação de suas decisões completamente distintos daqueles a que se submete o juiz". A decisão política presta conta de suas opções ao eleitorado, o juiz presta conta de suas decisões pelos parâmetros legais levados ao processo, como as provas acolhidas e os argumentos utilizados na decisão.

Além disso, o juiz deve, em cada fase do processo, fundamentar suas decisões, ao passo que na arena decisória do político, nem sempre há necessidade de fundamentação, o juízo do parlamentar, por exemplo, pode ser arbitrário.

A necessidade da fundamentação da decisão do órgão judicial é muito mais rigorosa do que a fundamentação do órgão administrativo, muito embora se saiba que algumas vezes o judiciário primeiro toma a decisão e depois dá a razão de decidir, ou seja, demonstra os seus fundamentos "dada a variedade das normas e o grande arsenal de técnicas argumentativas que séculos de dialética, jurídica ou não, forjaram, não é difícil motivar decisões, mesmo amplamente diversas sobre o mesmo objeto" (BOBBIO; MATTEUCCI; PASQUINO, 1991, p. 1161) ${ }^{10}$.

\footnotetext{
${ }^{10}$ Barroso (1998, p. 254) reproduz um trecho do voto do Min. Marco Aurélio, do STF nos seguintes termos: "ao examinar a lide, o magistrado deve idealizar a solução mais justa, considerada a respectiva formação humanista. Somente após, cabe recorrer à dogmática para, encontrado o indispensável apoio, formaliza-la]". Essa fala do Ministro retrata bem o que foi exposto, ou seja, o judiciário pri-
} 
O ex-Ministro do Supremo, Nelson Jobim, fez uma análise das diferenças de fundamentação na arena decisória do político e no âmbito do jurídico que merece ser transcrito:

não se pode pretender [...] que a fundamentação da decisão do parlamento tenha a mesma contextura, a mesma forma ou a mesma densidade das decisões do Poder Judiciário. [...] o procedimento pelo qual agem os parlamentares é absolutamente distinto do procedimento judicial. [...] A fundamentação da decisão política se encontra em qualquer peça ou momento do procedimento. Pode se encontrar no próprio projeto, no requerimento, na indicação, no parecer e na emenda - que são os tipos de proposições parlamentares -. Pode decorrer do debate quando da votação da matéria. O certo é que as decisões parlamentares não estão sujeitas às regras que disciplinam as decisões judiciais que impõem relatório, fundamentos e dispositivo (CPC, art. 458). O procedimento parlamentar é outro. O procedimento de tomada de decisões é outro. Logo, não se lhe aplica as regras de processo judicial, que é diverso. [...] Para as decisões judiciais, a lei impõe uma topologia própria e específica para os seus fundamentos. Não é o caso das decisões parlamentares. A localização dos fundamentos pode e é difuso. Os fundamentos podem se encontrar em diversos locus do processo decisório [...]. (BRASIL, 2000).

No mesmo sentido, Carvalho (2005) indica que o judiciário precisa justificar por escrito as suas decisões. Já os poderes políticos podem fazer escolhas sem explicações formais, podem apoiar-se em interesses e ideologias, ao passo que o judiciário só pode fundamentar suas decisões tendo em vista a base legal.

O processo decisório político, portanto, é amplo, global, mutável, passível de revisão, correção, prospectivo e sem necessidade de fundamentação rigorosa. O processo decisório judicial é limitado, casuístico, fragmentado, imutável, retrospectivo e amplamente fundamentado.

Outra diferença que pode ser apontada é o fato de que as decisões das cortes não passam de somatórios individuais dos votos, não se trata propriamente de uma deliberação colegiada. Os votos são seriados e depois somados, são proferidos isoladamente que depois de somados configuram a decisão da corte (FRIEDMAN, 2005). Difere, pois do processo decisório do legislativo no qual, em regra, há um acordo da maioria para a tomada de decisões.

Contudo, é sempre bom ressaltar que essas diferenças não podem ser levadas ao absoluto, pois o poder judiciário também faz parte dos poderes políticos da república e não há decisões apolíticas dentro do aparato estatal. As diferenças

meiro decide, para depois fundamentar suas decisões. 
são relacionadas aos procedimentos para a tomada de decisões.

Tendo em vista esse raciocínio, não se desconhece a função política do judiciário e mais ainda do Supremo Tribunal Federal, órgão máximo da justiça brasileira, que ao lado do Congresso Nacional e da Presidência da República formam os três poderes políticos do país. Como menciona Lima (2001), não há poder apolítico dentro do aparelho estatal. Também, segundo esse autor, pelo fato de o judiciário tomar decisões e ser responsável pelo desempenho da jurisdição, não se pode falar em manifestações apolíticas desse poder.

Entretanto, o que não se admite nas decisões judiciais são as decisões discricionárias ou meramente políticas. Conforme Lima (2001) tais decisões seriam aquelas que seguiriam os critérios de oportunidade e conveniência da autoridade política para a sua adoção.

No entanto, há autores, como Shapiro e Sweet (2002), que repudiam a ortodoxia na distinção entre lei e política, entre o legislador e o juiz e entre as maneiras legais de decidir e outras formas de tomadas de decisão, como as políticas.

Para Luhmann (1985, p. 34)

a diferenciação e a separação institucionais entre os processos legislativos e as decisões judiciais sobre disputas fazem parte dos dispositivos auto-evidentes das sociedades modernas com o direito positivo. Mas a interpretação dessa diferenciação ainda é imprecisa, e sua relação com a positivação do direito ainda tem que ser elaborada.

Contudo, Shapiro e Sweet (2002) mencionam que nas modernas democracias a legitimidade dos poderes políticos é conquistada pelas eleições livres e pela responsabilização dos governantes, ao passo que para o judiciário a legitimidade é assentada na sua pretensa independência e neutralidade e pelo fato dos juízes não serem atores políticos.

Para esses pesquisadores, tais atributos são reivindicações do próprio judiciário, entretanto, eles negam de antemão essas qualidades.

Essa pretensa neutralidade do judiciário se dá principalmente pelo fato de os principais analistas do judiciário serem pessoas ligadas ao próprio judiciário, como os advogados, por exemplo, que têm interesses na legitimidade das decisões das cortes. Contudo, analisando o modelo político norte-americano, Shapiro e Sweet (2002) mencionam que não dá para recusar e nem ignorar que o judiciário é um ator político ao passo que, como uma das ramificações constitucionais do poder, tem a atribuição de rever e vetar as ações e decisões dos dois outros ramos do poder político. Aqueles que negam o fato do judiciário ser um poder político estão revestidos de interesses, tal como os pesquisadores-advogados, que atribuem neutralidade ao judiciário para justificar as decisões conferidas aos seus processos, tenham êxito ou não. 
As próprias pesquisas acadêmicas sobre o judiciário demonstram isso. A ortodoxia das pesquisas acadêmicas do direito, comparadas com as pesquisas feitas por diferentes cientistas, em especial, pelas ciências sociais, revela que os pesquisadores-profissionais do direito, continuam a ser profissionais do direito e, nos trabalhos acadêmicos, defendem essa neutralidade do judiciário. Se de fato o judiciário é um poder político e age politicamente, esse fato deve ser escondido pelos juízes e por aqueles que dependem do judiciário, como é o caso dos advogados.

A atuação política do judiciário, muitas vezes, é camuflada pelo discurso legal e pela técnica da interpretação. Os juízes sempre alegam que estão decidindo de acordo com a lei e amparados estritamente na lei, porém, a interpretação envolve escolhas e opções, sendo que escolhas e opções são decisões políticas (SHAPIRO E SWEET, 2002).

Essa técnica argumentativa, segundo Habermas (2003, v. 2, p. 225), está prevista no ordenamento jurídico para que "os juristas possam entregar-se à ilusão de que não estão decidindo a seu bel-prazer.”.

Para Shapiro e Sweet (2002, p. 9) "a jurisprudência política deveria ser tratada como normal, natural, real e central e não como uma exceção a ser atacada.".

O judiciário deve sim ser compreendido como um poder independente, contudo, não neutro. Independente, pois possui verba orçamentária e autonomia decisória própria. Entretanto, não é um poder neutro, pois tem preferências e essas preferências algumas vezes se tornam claras e evidentes. Entretanto, não estão à disposição do processo decisório judicial outros critérios ou formas de decidir, senão aqueles pré estabelecidos pela legislação vigente.

Nesse mesmo sentido, Friedman (2005) aponta que nas pesquisas acadêmicas vinculadas aos cursos jurídicos, em geral, as análises sobre as decisões dos tribunais são estritamente legalistas. Entretanto, fora dos cursos de direito o foco é outro. A preocupação maior é de como e por que os juízes decidem desta ou daquela forma. Contudo, os juízes decidem no mundo político e separar a lei do mundo político não é plausível. Esse comportamento legalista do judiciário causa um insulamento dos juízes em relação à política e isso ocorre, pois esses profissionais chegam até a magistratura com um conjunto de orientações ideológicas e as aplicam na resolução dos conflitos.

Oliveira (2006) menciona que tendo em vista essa preocupação de descortinar as razões de decidir da justiça, nos Estados Unidos, as pesquisas sobre o processo decisório da justiça encontram-se bastante avançadas, havendo até uma linha de pesquisa acadêmica específica denominada naquele país de judicial politics. Dentro dessa linha de pesquisa há, ainda segundo a autora, quatro abordagens sobre o processo decisório da justiça estadunidense, são elas: atitudinal, 
estratégica, institucional e legal.

A abordagem atitudinal considera, em suas análises, as preferências políticas, os valores, as convicções ideológicas e o posicionamento ideológico-partidário do juiz, bem como a indicação presidencial, origem socioeconômica, pressão da opinião pública e composição congressual para a tomada de decisões judiciais (OLIVEIRA, 2006).

Segundo Koerner (2005), para essa abordagem, as decisões dos juízes refletem suas opções políticas, valores e interesses pessoais.

Desse modo, os juízes traduziriam suas preferências pessoais em jurisprudência constitucional, judicializando a política na conceituação de Tate (1994).

Essa corrente contrapõe-se, segundo Oliveira (2006), ao modelo de análise legal, que considera os juízes como atores neutros, que julgam conforme a lei e não fazem escolhas.

A corrente legalista compreende o direito como um subsistema, paralelo aos outros sistemas, sendo que o direito se reproduz por si só, sendo reconhecido como direito aquilo que é juridicamente decidido como direito, leva em consideração "que os juízes decidem os casos aplicando logicamente regras e princípios incorporados nos precedentes legais" (OLIVEIRA, 2006, p. 38).

Para a vertente estratégica as decisões dos juízes refletem preferências pessoais, contudo, "constrangidas por forças políticas, sociais e institucionais." (OLIVEIRA, 2006, p. 35).

Koerner (2005, p. 11) menciona que para essa corrente

os juízes não seguem estritamente suas preferências porque estão num contexto de relações estratégicas, no qual estão muito distanciadas as relações entre o conteúdo do voto do ministro, a decisão coletiva e seus efeitos políticos ou sociais.

Esse é o diferencial das correntes estratégicas e atitudinal.

Para a abordagem institucional, o direito é uma ferramenta da política e as cortes são agências políticas. Segundo esse modelo

é preciso considerar que as atitudes judiciais são elas mesmas constituídas e estruturadas pela corte como uma instituição e por sua relação com outras instituições no sistema político em pontos particulares da história. (OLIVEIRA, 2006, p. 37).

Para essa corrente de análise do judiciário é, segundo Oliveira (2006, p. 37), de fundamental importância levar-se em consideração o "desenvolvimento doutrinário da corte.". 


\section{CONSIDERAÇÕES FINAIS}

Esses apontamentos sobre as diferenças dos processos decisórios na justiça e na política, no trabalho de doutoramento, deram subsídios para a análise de alguns julgados do STF, no intuito de verificar qual é, de fato, a forma de julgar do Supremo Tribunal Federal. Se esse órgão julga juridicamente, se se utiliza de expediente político para a sua tomada de decisão ou se mescla as duas orientações no processo de tomada de decisões. No trabalho apontado chegou-se a conclusão, que em casos difíceis, muitas vezes o STF julga os processos adotando critérios de julgamento político em detrimento dos critérios estritamente legais. Espera-se também que este trabalho sirva como instigação para outras pesquisas acadêmicas no sentido da interpretação dessas diferenças apontadas.

\section{REFERÊNCIAS}

BARROSO, L. R. Interpretação e aplicação da constituição: fundamentos de uma dogmática constitucional transformadora. 2. ed. São Paulo: Saraiva, 1998.

BOBBIO, N.; MATTEUCCI, N.; PASQUINO, G. Dicionário de política. Brasília: UnB, 1991. 2 v.

BRASIL. Lei 5.869, de 11 de janeiro de 1973. Disponível em: < http://www. presidencia.gov.br>. Acesso em: 14 jun. 2006.

. Constituição (1988). Constituição da República Federativa do

Brasil: promulgada em 5 de outubro de 1988. Disponível em: <http://www. presidencia.gov.br>. Acesso em: 14 jun. 2006.

. Supremo Tribunal Federal. Mandado de Segurança n. 23575, 21 de janeiro de 2000. Disponível em: $<$ http://www.stf.gov.br $>$. Acesso em: 05 set. 2006.

CAMPILONGO, C. F. Política, sistema jurídico e decisão judicial. São Paulo: Max Limonad, 2002.

CAPPELLETTI, M. Juízes legisladores? Porto Alegre: SAFE, 1993.

CARVALHO, E. R. de. Revisão abstrata da legislação e a judicialização da política no Brasil. 2005. 157 f. Tese (Doutorado em Ciência Política) Universidade de São Paulo, São Paulo, 2005. 
CINTRA, A. C. de A.; GRINOVER, A. P.; DINAMARCO, C. R. Teoria geral do processo. 2. ed. São Paulo: Revista dos Tribunais, 1979.

FARIA, J. E. O sistema brasileiro de justiça: experiência recente e futuros desafios. Estudos Avançados, São Paulo, v. 18, n. 51, p. 103-125, 2004.

FRIEDMAN, B. The politics of judicial review. Texas Law Review. Austin, v. 84, n. 2, p. 257-337, dez. 2005.

HABERLE, P. Hermenêutica constitucional. Porto Alegre: SAFE, 1997.

HABERMAS, J. Direito e democracia: entre facticidade e validade. Rio de Janeiro: Tempo Brasileiro, 2003. $2 \mathrm{v}$.

KOERNER, A. Direito e modernização periférica: por uma análise sóciopolítica do pensamento constitucional brasileiro pós-1988. In:

Encontro anual da Anpocs, Caxambú, n. 28, 2005.

LIMA, F. G. M. de. O Supremo Tribunal Federal na crise institucional brasileira. Fortaleza: ABC Fortaleza, 2001.

LUHMANN, N. Sociologia do direito II. Rio de Janeiro: Tempo Brasileiro, 1985.

MARCATO, A. C. Procedimentos especiais. 6. ed. São Paulo: Malheiros, 1994.

MAUS, I. Judiciário como superego da sociedade. O papel da atividade jurisprudencial na sociedade órfã. Novos Estudos Cebrap, São Paulo, n. 58, p. 183-202, nov. 2000.

MORO, S. F. Jurisdição constitucional como democracia. São Paulo: Revista dos Tribunais, 2004.

OLIVEIRA, F. L. Justiça, profissionalismo e política: O Supremo Tribunal Federal e o controle da constitucionalidade das leis no Brasil (1988-2003). 2006. 249 f. Tese (Doutorado em Ciências Sociais) - Centro de Educação e Ciências Humanas, Universidade Federal de São Carlos, São Carlos, 2006.

SHAPIRO, M.; SWEET, A. S. On law, politics, and judicialization. Oxford: Oxford University Press, 2002. 
SOUZA, M. T. A reforma do judiciário brasileiro no circuito decisório da Câmara dos Deputados. Perspectiva, São Paulo, n. 27, p. 69-81, 2005.

TAYLOR, M. M. O judiciário e as políticas públicas no Brasil. Dados, Rio de Janeiro, v. 50, n. 2, p. 229-257, 2007.

TATE, C. N. Why the expansion of judicial power?. In: TATE, C. N.; VALLINDER, T. The global expansion of judicial power. New York: New York University Press, 1994. p. 25-36.

THEODORO JUNIOR, H. Curso de direito processual civil. 23. ed. Rio de Janeiro: Forense, 1998. v. I.

UNGER, R. M. O direito na sociedade moderna. Rio de Janeiro: Civilização Brasileira, 1976.

VALLINDER, T. When the courts go marching in. In: TATE, C. N.; VALLINDER, T. The global expansion of judicial power. New York: New York University Press, 1994. p. 10-23.

VIEIRA, O. V. A constituição e sua reserva de justiça: um ensaio sobre os limites materiais ao poder de reforma. São Paulo: Malheiros, 1999.

Malheiros, 2002.

. Supremo Tribunal Federal: jurisprudência política. 2. ed. São Paulo:

\title{
DIFFERENCES IN JUDICIAL DECISION-MAKING PROCESS AND POLITICAL POWERS
}

\begin{abstract}
This paper is part of the doctoral work that investigates the hypothesis of legalizing the politics in the Supreme Court. This study subsidized the doctoral work in the sense of pointing out a few of the differences in the judicial and political decision-making processes and by defining if the legalization hypothesis was confirmed. This study aims to exercise the appointment of these differences, given the scarcity of specific bibliography on the subject and the theoretical uncertainty in the interpretation of these differences.
\end{abstract}

KEYWORDS: Decision-making process; Policy; Law; Judiciary. 


\section{DIFERENCIAS DE PROCESO DECISORIO DEL JUDICIARIO Y DE LOS PODERES POLÍTICOS}

RESUMEN: Este estudio es parte integrante del trabajo de doctorado en que se ha investigado la hipótesis de judicialización de la política en el Supremo Tribunal Federal. El estudio que se presenta subsidió el trabajo de doctorado en el sentido de apuntar algunas diferencias existentes en los procesos decisorios judiciarios y en los políticos, y definir si la hipótesis de judicialización se confirmaba. Este estudio ha buscado ejercitar apuntes de esas diferencias, teniendo en cuenta la escasez de bibliografía específica sobre el tema y la imprecisión teórica en la interpretación de esas diferencias.

PALABRAS CLAVE: Proceso decisorio; Política; Derecho; Judiciario. 